\title{
PERAN DAN STRATEGI KELOMPOK "KOTAK KOSONG" DALAM PILKADA CALON TUNGGAL KABUPATEN PATI TAHUN 2017: STUDI PENDAHULUAN
}

\author{
Ikhsan Darmawan \\ Departemen Ilmu Politik Universitas Indonesia, Depok, Indonesia \\ E-mail: ikhsan_darmawan@yahoo.com
}

\begin{abstract}
ABSTRAK
Pilkada calon tunggal tahun 2017 yang dilaksanakan pada 15 Februari 2017 menyisakan sebuah fenomena politik yang menarik. Dari 101 daerah (provinsi, kabupaten, dan kota) yang menyelenggarakan Pilkada, ada 9 (sembilan) daerah yang Pilkada-nya terdiri dari calon tunggal. Kasus paling menarik adalah Pilkada di Pati. Dibandingkan dengan delapan daerah lain, jumlah suara yang diperoleh oleh pilihan "kotak kosong" di Pati adalah yang tertinggi di antara daerah lain. Selain itu, tidak seperti tujuh daerah lain, di Pati ada sebuah kelompok yang menyuarakan pilihan "kotak kosong" seperti di Kabupaten Buton. Artikel ini mencoba menjawab pertanyaan: "Bagaimana peran dan strategi dari kelompok "kotak kosong" dalam Pilkada Calon Tunggal di Kabupaten Pati Tahun 2017?" Penelitian ini menggunakan pendekatan kualitatif dengan metode pengumpulan data: wawancara mendalam, observasi, dan pengumpulan berita dari internet. Penelitian ini menemukan bahwa peran dari kelompok "kotak kosong" adalah memfokuskan pada isu yang spesifik dan menguntungkan anggota mereka, meningkatkan level mereka, dan menggunakan kekuasaan mereka. Selain itu, kelompok "kotak kosong" menggunakan strategi, seperti menggunakan strategi lobi, membuka akses ke pembuat kebijakan dan memobilisasi sumber daya mereka, memobilisasi pemilih, mengontrol informasi kepada pemilih, dan melakukan advokasi.
\end{abstract}

Kata Kunci: peran dan strategi, kelompok kepentingan, Pati, Pilkada calon tunggal

\section{ROLE AND STRATEGIES OF GROUP OF “KOTAK KOSONG” IN PATI SINGLE CANDIDATE LOCAL ELECTION 2017}

\begin{abstract}
Simultaneous local election 2017 which was held in February 15th, 2017 remains an interesting political phenomenon. From 101 areas (province, municipality, and city) that held local elections, there are 9 (nine) areas whose local election consist of single candidate. The most interesting case is Local Election in Pati. Compared with other eight areas, the amount of votes gained by "kotak kosong" in Local Election in Pati is the highest among the others. Besides that, unlike other seven areas, in Pati there is a group that propose choice of "kotak kosong" like in Buton Municipality. This article tries to answer question: "How are the roles and strategies of group of "kotak kosong" in Pati Single Candidate Local Election 2017? This research uses the qualitative approach with the method of data collections are: depth interviews, observation, and collecting news related from internet. This research reveals that the roles of group of "kotak kosong" are focusing on the specific isu and benefiting their members, increasing their level, and using their power. Besides that, the group of "kotak kosong" used strategies, such as using lobby strategy, opening the access to policy makers and mobilizing their resources, mobilizing voters, controlling information to voters, and doing advocacy.
\end{abstract}

Keywords: role and strategy, interest group, Pati, single candidate local election 


\section{PENDAHULUAN}

Pilkada Serentak tahun 2017 yang digelar pada 15 Februari 2017 menyisakan fenomena yang menarik. Di antara total 101 daerah (provinsi, kabupaten, atau kota) yang menggelar Pilkada, ada 9 daerah yang dalam Pilkadanya terdiri dari satu pasang calon atau lebih dikenal dengan nama calon tunggal. Kesembilan daerah itu antara lain: Kabupaten Pati, Kabupaten Buton, Kabupaten Tulang Bawang Barat, Kota Tebing Tinggi, Kabupaten Landak, Kabupaten Maluku Tengah, Kota Jayapura, Kabupaten Tambrauw, dan Kota Sorong.

Pilkada Kabupaten Pati adalah salah satu yang paling menarik. Ada beberapa sebab mengapa Pilkada Kabupaten Pati tahun 2017 merupakan yang paling menarik. Pertama, Pilkada Kabupaten Pati adalah satu-satunya Pilkada calon tunggal pada tahun 2017 di pulau Jawa. Sebelumnya, di Pilkada Serentak tahun 2015, ada dua daerah di Pulau Jawa yang Pilkadanya terdiri dari calon tunggal, yakni Pilkada Kabupaten Tasikmalaya dan Pilkada Kabupaten Blitar.

Kedua, meskipun secara persentase persentase perolehan suara Kabupaten Pati nomor tiga terbesar dibandingkan dengan Kabupaten Maluku Tengah $(29,15 \%)$ dan Kota Tebing Tinggi (28,61\%), akan tetapi perolehan suara "kotak kosong" di Pilkada Kabupaten Pati adalah yang tertinggi di Indonesia (177.694 atau 25,48\%) (lihat Tabel 1). Memang jumlah pemilih di Kabupaten Pati adalah paling tinggi dibandingkan dengan delapan daerah lain. Akan tetapi, pada dasarnya jumlah pemilih tertinggi itu bukanlah sebuah jaminan bahwa jumlah pemilih "kotak kosong" pasti akan lebih atau bahkan paling tinggi di antara daerah lain.

Ketiga, dibandingkan dengan daerah lain, di Kabupaten Pati terdapat sebuah kelompok yang menyuarakan "kotak kosong" yang fenomenal. Kelompok yang menamakan diri dengan Aliansi Kawal Demokrasi Pilkada (AKDP) Kabupaten Pati ini melakukan kegiatan menyuarakan dan memperjuangkan pilihan "kotak kosong" sejak Oktober 2016 atau lima bulan sebelum Pilkada. Sementara itu, di daerah lain, seperti Kabupaten Buton, Forum Amanah Masyarakat Buton baru melakukan aksi demonstrasi beberapa hari sebelum Pilkada, yaitu pada tanggal 6 Februari 2017 (Neke, 2017).
Tabel 1. Hasil Sembilan Pilkada Calon Tunggal Tahun 2017

\begin{tabular}{clll}
\hline No. & Nama Daerah & Petahana & \multicolumn{1}{c}{$\begin{array}{c}\text { Kotak } \\
\text { Kosong }\end{array}$} \\
\hline 1 & Pati & $\begin{array}{l}74,52 \% \\
(519.610)\end{array}$ & $\begin{array}{l}25,48 \% \\
(177.694)\end{array}$ \\
& & $55,08 \%$ & $44,92 \%$ \\
2 & Buton & $(27.512)$ & $(22.438)$ \\
& & $96,75 \%$ & $3,25 \%$ \\
3 & Tulang Bawang & $(167.512)$ & $(5.625)$ \\
& Barat & & \\
& & $71,39 \%$ & $28,61 \%$ \\
4 & Kota Tebing & $(41.937)$ & $(16.807)$ \\
& Tinggi & $96,72 \%$ & $3,28 \%$ \\
5 & Landak & $(226.378)$ & $(7.673)$ \\
& & $70,85 \%$ & $29,15 \%$ \\
6 & Maluku Tengah & $(58.681)$ \\
& & $(142.644)$ & $15,47 \%$ \\
7 & Kota Jayapura & $84,53 \%$ & $(19.213)$ \\
& & $(104.993)$ & $12,93 \%$ \\
8 & Tambrauw & $87,07 \%$ & $(715)$ \\
& & $(4.814)$ & $20,63 \%$ \\
9 & Kota Sorong & $79.37 \%$ & $(12.262)$ \\
\hline
\end{tabular}

Sumber: Diolah penulis dari website KPU.

Pilkada Kabupaten Pati sendiri sampai artikel ini dikerjakan telah selesai sampai tahap rekapitulasi tingkatkabupaten. Berdasarkan hasil rekapitulasi yang dilaksanakan pada tanggal 23 Februari 2017 lalu, pasangan Haryanto-Saiful Arifin berhasil meraih 519.675 suara (atau $74,5 \%$ ) dari total 697.437 suara sah. Sementara, pilihan "kotak kosong" mendapat 177.762 suara (atau 25,5\%) (Roziki, 2017).

Perolehan suara "kotak kosong"yang tinggi merupakan hal yang tidak mudah. Kelompok "kotak kosong" tidak mendapat fasilitas dari negara sehingga harus membiayai sendiri kampanye mereka. Selain itu, kelompok "kotak kosong" tidak diberi kesempatan yang leluasa untuk menyampaikan dan mengkampanyekan suara mereka. Acara deklarasi AKDP Kabupaten Pati pada 22 Desember 2016 diminta tidak dilanjutkan oleh Panwas Kabupaten Pati karena harus mendapatkan rekomendasi dari Kabupaten Pati (Jurnal Sumatera, 2016). Padahal, Ketua KPU RI, Juri Ardiantoro mengatakan pada Oktober 2016, bahwa masyarakat di Kabupaten Pati dibolehkan melakukan kampanye "kotak kosong" (Akhmad NL, 2016). Oleh karenanya, dengan situasi tidak mudah itu namun kemudian perolehan suara kelompok "kotak kosong" paling tinggi dibandingkan dengan daerahdaerah lain menimbulkan pertanyaan menarik 
untuk dijawab. Berdasarkan latar belakang di atas, artikel ini berusaha menjawab pertanyaan: "Bagaimana peran dan strategi dari kelompok "kotak kosong" dalam Pilkada Calon Tunggal di Kabupaten Pati Tahun 2017'?

Dikarenakan Pilkada calon tunggal merupakan fenomena yang relatif baru, maka penelitian sebelumnya tentang Pilkada calon tunggal belum terlalu banyak. Beberapa di antaranya yaitu penelitian tentang kelompok "tidak setuju" di ketiga daerah dalam Pilkada calon tunggal tahun 2015 (Darmawan, 2017), penelitian tentang kaitan antara Pilkada calon tunggal dan demokrasi (Dhesinta, 2016), kajian singkat tentang Pilkada calon tunggal dalam Pilkada Serentak tahun 2015 (Ardipandanto, 2015), dan kajian hukum tentang mekanisme referendum dalam Pilkada calon tunggal (Prabagdo, 2016). Posisi dan kontribusi dari penelitian ini adalah memberikan penjelasan tentang bagaimana peran dan strategi kelompok "kosong" dalam Pilkada Calon Tunggal di Kabupaten Pati Tahun 2017

Sebagai pisau analisis, artikel ini menggunakan beberapa teori terkait dengan kelompok kepentingan, yaitu: pengaruh kelompok kepentingan, peran kelompok kepentingan, dan strategi kelompok kepentingan.

Kelompok kepentingan dinilai memiliki pengaruh. Telah banyak riset yang membahas tentang pengaruh kelompok kepentingan. Salah satunya adalah temuan Coughlin dkk (1990) berkaitan dengan pengaruh kelompok kepentingan terhadap bertambahnya size of government ketika bertemu dengan faktor-faktor lain, seperti faktor pajak atau keuntungan dari pajak. Ada juga temuan Dur dan Bievre (2007: 1) di mana pengaruh dari kelompok kepentingan dapat menyebabkan pembuat kebijakan tidak dapat menghasilkan kebijakan secara efektif. Ada juga pengaruh kelompok kepentingan di Uni Eropa. Hanya saja, temuan Dur (2008: 1212) ternyata terdapat catatan dari kelompok kepentingan di Uni Eropa di mana mereka menemui sejumlah kendala atau tantangan.

Menurut Etzioni (1985: 171-172), kelompok kepentingan memiliki beberapa peran. Pertama, memfokuskan pada isu tertentu dan menguntungkan anggota mereka sendiri. Kedua, meningkatkan level atau tingkat yang ingin mereka capai. Ketiga, menggunakan power atau kekuasaan yang mereka miliki.
Kelompok kepentingan memiliki bermacam jenis strategi dalam usaha mencapai tujuan mereka. Pertama, kelompok kepentingan dapat menggunakan strategi lobi. Lobi itu sendiri pun disesuaikan dengan konteks kepentingan masing-masing (De Bruyker, 2014; Weiler dkk, 2014; Rasmussen, 2012).

Strategi kedua dari kelompok kepentingan adalah dengan membuka akses kepada pembuat kebijakan dan memobilisasi sumber daya yang mereka miliki (Baumgartner, 2009: 519; Damore dan Nicholson, 2013; Anzia, 2010: 1; Steel dkk, 1996: 1).

Strategi ketiga adalah kelompok kepentingan dapat memobilisasi pemilih agar dapat mempengaruhi hasil pemilu. Kelompok kepentingan bahkan dapat melakukan kepada individu-individu (Clouse, 2008; Schwartz, 2002: 1845).

Strategi keempat adalah dengan mengontrol informasi kepada pemilih pada umumnya. Strategi ini dilakukan karena kelompok kepentingan memiliki sumber daya yang terbatas (Alston dkk, 2005: 1). Dengan bahasa lain, strategi ini disebut dengan membentuk opini publik dengan membentuk kerangka (frame) dikarenakan kelompok kepentingan memiliki keterbatasan sumber daya (Dur, 2016).

Strategi kelima adalah dengan melakukan advokasi. Advokasi yang dimaksud di sini adalah dengan cara memperbesar dan memperluas koalisi atau jumlah pendukung (Scaramuzzino dkk, 2013).

\section{METODE PENELITIAN}

Penulis dalam penelitian ini menggunakan pendekatan kualitatif. Pendekatan kualitatif dipilih dengan pertimbangan penulis yaitu pendekatan ini lebih menekankan pada kedalaman data dan penjelasan ketimbang pendekatan kuantitatif.

Metode pengumpulan data yang digunakan adalah wawancara mendalam, observasi, dan pengumpulan berita terkait dari internet. Wawancara mendalam dan observasi dilakukan pada bulan Februari 2017. Bahkan, penulis melakukan observasi pada hari-H Pilkada Kabupaten Pati (15 Februari 2017) demi mendapatkan pengalaman melihat langsung hal-hal terkait dengan topik dan pertanyaan penelitian. 


\section{HASIL DAN PEMBAHASAN}

Kelompok "kotak kosong" pada Pilkada Kabupaten Pati tahun 2017 merupakan kelompok yang ingin menyuarakan agar masyarakat Kabupaten Pati tidak lagi dipimpin oleh Bupati Pati petahana, Haryanto. Kelompok "kotak kosong" pada Pilkada Kabupaten Pati tahun 2017 menamakan diri mereka dengan Aliansi Kawal Demokrasi Pilkada (AKDP) Kabupaten Pati. AKDP diketuai oleh Sutiyo dan dideklarasikan di rumah salah seorang mantan kepala desa di tempat deklarasi. Menurut Ketua AKDP, Sutiyo, "Kampanye kotak kosong ini sebagai pendidikan berdemokrasi, karena warga harus diberikan pilihan dan suara mereka juga berharga" (Safuan, 2016).

Menurut Sutiyo, AKDP hadir untuk menyuarakan dukungan terhadap "kotak kosong". Dalam menyuarakan dukungan itu, AKDP menghadapi masalah di mana izin sejak deklarasi sampai kampanye dipersulit baik oleh Panwas, KPU, maupun Kepolisian. AKDP tidak diberi izin oleh pihak berwenang meski sudah meminta rekomendasi kepada KPU. KPU Kabupaten Pati mengatakan bahwa izin adalah ranah Kepolisian. Ketika pihak AKDP mendatangi Kepolisian, dijawab oleh Kepolisian bahwa wajib mendapat rekomendasi dari KPU. AKDP merasa “dipimpong” (Safuan, 2016).

Deklarasi yang rencananya dilaksanakan pada 22 Desember 2016 pukul 14:00 WIB di rumah Karyo, mantan Kades Tlogoayu (lihat Gambar 4) setelah ditunggu sampai pukul 17:00 WIB gagal dilaksanakan karena Panwas Kabupaten Pati menyarankan agar AKDP tidak melanjutkan kegiatan deklarasi demi menjaga situasi tetap kondusif. "Kami tidak melarang kegiatan masyarakat yang tergabung dalam AKDP mengingat kegiatan kampanye sekalipun tidak ada aturan yang mengaturnya," kata anggota Panwas Kabupaten Pati Moh Rifa'i (jurnalsumatra.com, 2016).

Sementara itu, Kapolres Pati AKBP Ari Wibowo menegaskan bahwa pihaknya tidak membubarkan acara tersebut. "Kehadiran kami hanya sebatas mengawal kegiatan tersebut agar berjalan dengan tertib dan tidak ada hal-hal yang tidak diinginkan semua pihak," ujarnya (jurnalsumatra.com, 2016).

Peran AKDP dalam Pilkada calon tunggal Kabupaten Pati Tahun 2017 adalah dengan melakukan beberapa hal. Pertama, dengan memfokuskan pada isu-isu tertentu. Menurut Itqonul Hakim (wawancara langsung), Sekretaris AKDP,AKDP fokus pada isu tertentu seperti rencana pembangunan pabrik semen di wilayah Kendeng, Kabupaten Pati, yang bersebelahan dengan Kabupaten Rembang. Di samping itu, AKDP juga mensosialisasikan kegagalan dari bupati petahana, Haryono, baik kepada masyarakat langsung maupun melalui media massa.

Selain itu, AKDP juga melakukan kegiatan yang menguntungkan anggota mereka. Kegiatan dimaksud adalah dengan mempromosikan kegiatan-kegiatan mereka melalui media sosial maupun media massa. Dengan promosi kegiatan tersebut diharapkan dapat memperbesar jumlah dukungan terhadap pilihan "kotak kosong".

Peran lain dari AKDP adalah dengan meningkatkan level atau tingkat yang ingin mereka capai. Peran itu dilakukan AKDP dengan cara mendiseminasikan di media massa sebelum Pilkada berlangsung bahwa pilihan "kotak kosong" akan meraih suara sebesar $70 \%$.

Peran berikutnya adalah dengan menggunakan power atau kekuasaan yang mereka miliki. Mengenai peran ini, AKDP yang sudah mendapatkan jumlah anggota yang banyak di media sosial (facebook) dan sudah menjadi media darling memiliki keberanian untuk menyampaikan kepada Panwaslu bahwa tim sukses bupati petahana telah melakukan politik uang. Bahkan, sebelum itu mereka berani untuk melaporkan Panwaslu Kabupaten Pati ke Dewan Kehormatan Penyelenggara Pemilu (DKPP) atas tindakan Panwaslu tidak mengizinkan dilakukannya deklarasi AKDP. Keseluruhan peran-peran dari AKDP seperti diuraikan di atas sejalan dengan peran kelompok kepentingan menurut Etzioni.

Pertama, kelompok kepentingan dapat menggunakan strategi lobi disesuaikan dengan konteks kepentingan masing-masing. Strategi lobi yang dilakukan oleh AKDP adalah dengan melobi pihak-pihak terkait penyelenggaraan Pilkada seperti KPU, Panwas, dan Kepolisian, bahwa merekaberhak untuk menyelenggarakan kegiatan sosialisasi dan kampanye pilihan "kotak kosong".

Strategi kedua dari kelompok kepentingan adalah dengan membuka akses kepada pembuat kebijakan dan memobilisasi sumber daya yang mereka miliki. Pembukaan akses kepada 
pembuat kebijakan dilakukan AKDP dengan cara membuat mereka dikenal oleh media massa sehingga menjadi media darling. Dengan menjadi media darling, mereka memiliki daya tawar lebih di mata pembuat kebijakan. Sementara itu, memobilisasi sumber daya dilakukan AKDP dengan mengadakan deklarasi yang mengundang seluruh warga Kabupaten Pati yang mendukung gerakan dan kepentingan mereka.

Strategi ketiga adalah kelompok kepentingan dapat memobilisasi pemilih agar dapat mempengaruhi hasil pemilu. AKDP berusaha menggalang pilihan dan mobilisasi suara pemilih agar memilih "kotak kosong" dengan menggunakan medium Facebook Group. Ada dua Facebook Group yang aktif atau online yaitu "Relawan Kotak Pati" (lihat Gambar 1) dan "Relawan Kotak Kosong Pati Bumi Mina" (lihat Gambar 3).

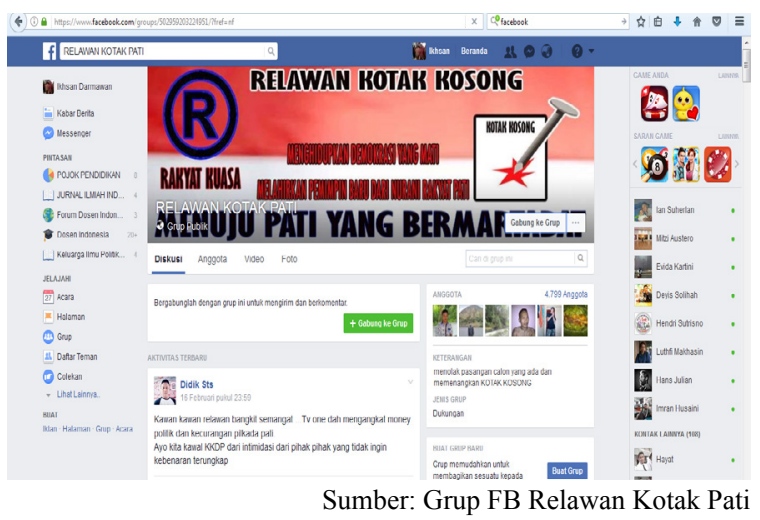

Gambar 1. Grup Facebook Relawan Kotak Pati

Jumlah anggota grup "Relawan Kotak Pati" mencapai 4.799 akun (lihat Gambar 2). Sementara itu, jumlah anggota grup "Relawan Kotak Kosong Pati Bumi Mina" sebanyak 4.224 akun.

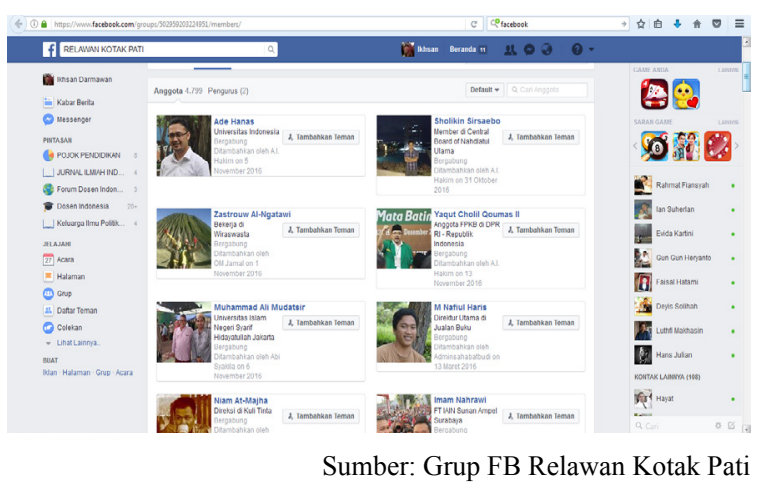

Gambar 2. Halaman Anggota Grup Facebook Relawan Kotak Pati

Kedua grup memiliki sejumlah aktivitas seperti posting kegiatan, berita, dan per- kembangan yang terjadi sebelum dan menjelang hari-H Pilkada. Tak terkecuali, ketika mencoba mengumpulkan dana lewat penjualan kaus bertemakan "kotak kosong", kedua grup facebook digunakan sebagai sarana atau media yang cukup efektif.

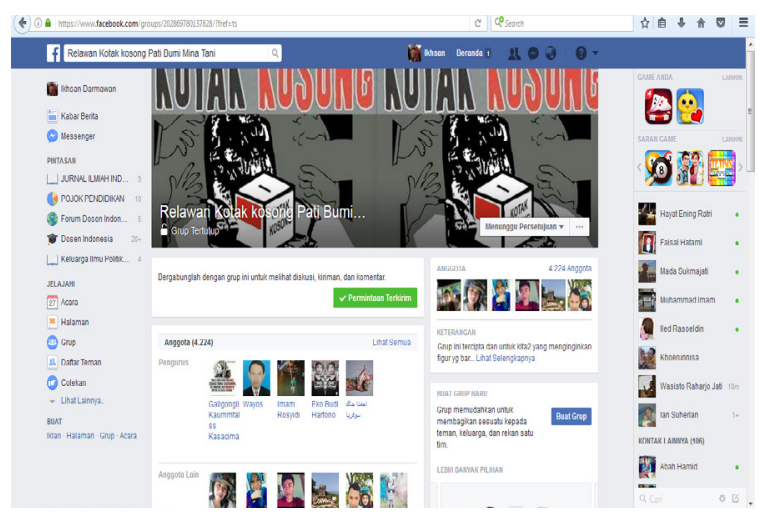

Sumber: Grup FB Relawan Kotak Kosong Pati Bumi Mina

Gambar 3. Halaman Anggota Grup Facebook Relawan Kotak Kosong Pati Bumi Mina

Strategi berikutnya adalah dengan mengontrol informasi kepada pemilih pada umumnya dengan membentuk opini publik dengan membentuk kerangka (frame) karena mereka memiliki sumber daya yang terbatas. Tidak seperti pasangan calon petahana yang mendapat alokasi dana kampanye dari negara, menurut Karyo salah satu pengurus AKDP, AKDP memiliki keterbatasan sumber daya. "Kami tidak memiliki sponsor seperti yang disebut-sebut pihak lain. Kami benar-benar menggunakan dana sendiri yang digalang secara sukarela" (Karyo, wawancara langsung).

Kelompok "kotak kosong" juga berusaha untuk mendapat perhatian. Salah satunya dengan memasang spanduk untuk memilih "kotak kosong" yang dipasang di salah satu Posko di Desa Tlogoayu, Kecamatan Gabus, Kabupaten Pati. Tujuan dipasangnya spanduk di Posko yang terletak di pinggir jalan itu adalah agar mendapat perhatian baik dari masyarakat sekitar dan yang melintasi Posko tersebut atau menarik perhatian media massa lokal.

Tidak hanya sebelum hari-H, pada saat hari-HAKDPjuga melakukanusaha pengawalan terhadap proses pemilihan dan penghitungan suara. Tujuannya adalah agar mereka dapat memastikan bahwa tidak ada kecurangan yang terjadi (lihat Gambar 5).

Strategi kelima dari AKDP adalah dengan melakukan advokasi dengan cara memperbesar dan memperluas koalisi atau 


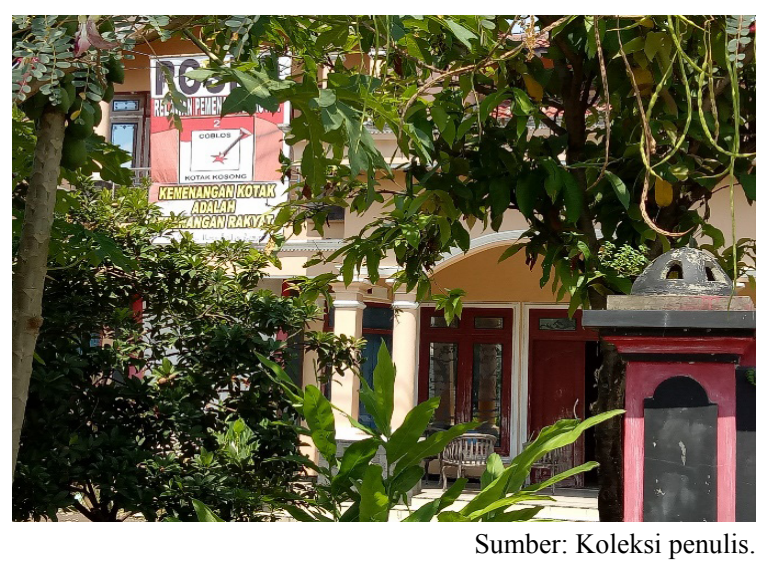

Gambar 4. Suasana Salah Satu Posko Kelompok Kotak Kosong di Desa Tlogoayu

jumlah pendukung. AKDP secara giat dan gencar berusaha meraih kepercayaaan dan dukungan dari pemilih melalui semua cara yang memungkinkan. Perluasan jumlah pendukung lewat media sosial yang menyasar pemilih anak muda juga diimbangi dengan pemasangan spanduk yang kemudian menimbulkan reaksi dari tim sukses bupati petahana. Reaksi itu berupa dicopotnya spanduk AKDP dan kemudian pencopotan spanduk itu menjadi berita di media massa lokal. Dari situ, jumlah pendukung yang memberi simpati dan dukungan semakin besar.

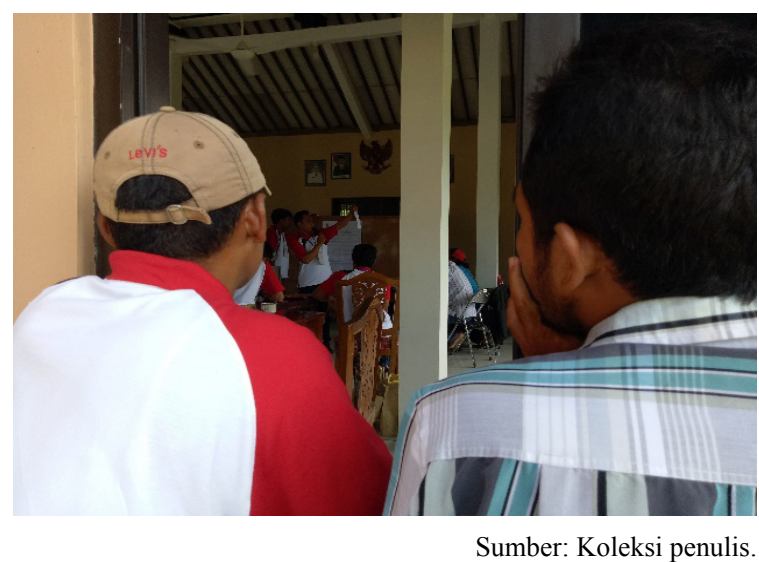

Gambar 5. Suasana Penghitungan Suara di TPS 03 Desa Tlogoayu

\section{SIMPULAN}

Artikel ini membahas tentang bagaimana peran dan strategi kelompok "kotak kosong" dalam Pilkada Kabupaten Pati Tahun 2017. Artikel ini menemukan bahwa peran AKDP adalah dengan memfokuskan pada isu tertentu dan menguntungkan anggota mereka sendiri, meningkatkan level atau tingkat yang ingin mereka capai, dan menggunakan power atau kekuasaan yang mereka miliki.

Selain itu, AKDP juga memiliki lima strategi. Strategi-strategi itu adalah menggunakan strategi lobi, membuka akses kepada pembuat kebijakan dan memobilisasi sumber daya yang mereka miliki, memobilisasi pemilih, mengontrol informasi kepada pemilih pada umumnya, dan melakukan advokasi.

\section{DAFTAR PUSTAKA}

Akhmad NL. (2016, Oktober 23). KPU: Masyarakat Pati Boleh Kampanye Kotak Kosong.

Alston, Lee J., Gary D. Libecap, dan Bernardo Mueller, How Interest Groups with Limited Resources can Influence Political Outcomes: Information Control and the Landless Peasant Movement in Brazil, Working Paper, 2005.

Anzia, Sarah F. (2010). Election Timing and the Electoral Influence of Interest Groups.

Ardipandanto, Aryojati. (2015). Calon Tunggal dalam Pilkada Serentak 2015. Info Singkat Pemeritahan Dalam Negeri, Vol. VII, No. 15/I/P3DI/Agustus/2015.

Baumgartner, Frank R. (2009). Interest Groups and Agendas.

Clouse, Clayton. (2008). Interest Groups Influence Through Voter Mobilization. Interest Groups and Public Policy.

Coughlin, Peter J., Mueller, Dennis C. dan Petter Murrell,. (1990). Electoral Politics, Interest Groups, and the Size of Government. Economic Inquiry, 28(4), 682-705.

Damore, David F. dan Stephen P. Nicholson. (2013). Mobilising Interests: Group Participation and Competition in Direct Democracy Elections. Polit Behav.

Darmawan, Ikhsan. (2017). Tidak Diakomodirnya Kelompok "Tidak Setuju” dalam Pilkada Calon Tunggal Tahun 2015, manuskrip artikel untuk Jurnal Politica. (dalam proses penerbitan).

De Bruycker, Iskader, How Interest Groups Develop Their Lobbying Strategies: 
The Logic of Endogeneity, Paper presented for the ECPR's General Conference 2014, Glasgow.

Dhesinta, Wafia Silvi. (2016). Calon Tunggal dalam Pemilihan Umum Kepala Daerah dan Konsep Demokrasi: Analisis Terhadap Pemilihan Kepala Daerah Kabupaten Blitar Tahun 2015. Jurnal Cita Hukum. 4(1). 87-104.

Dur, Andreas dan Dirk De Bievre,. (2007). The Question of Interest Group Influence. Journal Public Policy, 27(1), 1-12.

. (2008). Interest Groups in the European Union: How Powerful Are They?, West European Politics, 31(6), 1212-1230

. (2016). How Interest Groups Influence Public Opinion: Arguments Matter More Than The Sources.

Etzioni, Amitai, (1985). Special Interest Groups Versus Constituency Representation. Research in Social Movements, Conflicts, and Change, 8, 171-195.

Jurnal Sumatera. (2016, Desember 23). Kampanye Kotak Kosong di Pati Mulai Muncul.

Neke, Defriatno, (2017, Februari 6). Sekelompok Warga Kampanyekan Kotak Kosong untuk Pilkada Buton.

Roziki, Yayan Isro, (2017, Februari 23). Ini Hasil Rekapitulasi Suara Pilkada Pati, Kotak Kosong Dipilih Lebih Dari 170 Ribu Warga. Tribun Jateng.

Prabagdo, Herdito, Mekanisme Referendum dalam Pemilihan Umum Kepala Daerah Calon Tunggal, Skripsi Fakultas Hukum Universitas Airlangga, 2016.

Rasmussen, Maja Kluger, The Influence of Interest Groups in the European Parliament: Does Policy Shape Politics, Ph.D Dissertation in London School of Economics, 2012.
Roziki, Yayan Isro, (2017, Februari 23). Ini Hasil Rekapitulasi Suara Pilkada Pati, Kotak Kosong Dipilih Lebih Dari 170 Ribu Warga. Tribun Jateng.

Safuan, Akhmad, (2016, Desember 26). Pilkada Pati, Kotak Kosong Mulai Kampanye.

Scaramuzzino, R., Markus Wennerhag, dan Hakan Johansson. (2013). Mobilisation, advocacy and influence: Swedish interest groups and social movement organizations compared. Diakses 26 Februari 2017, dari: http://eurociv.blogg. lu.se/files/2013/01/Scaramuzzino Wennerhag_Johansson_ECPR2014.pdf.

Schwartz, Daniel J., "The Potential Effects of Non-Deferential Review On Interest Group Incentives and Voter Turnout", New York University Law Review, Vol. 77: 1845-1882., 2002.

Steel, Brian, John C. Pierce, dan Nicholas P. Lovrich,. (1996). Resources and Strategies of Interest Groups and Industry Representatives Involved in Federal Forest Policy, The Social Science Journal, 33(4), 401-409.

Weiler, Florian, Matthias Brandli, Ottfried Jarren, dan Patrick Donges, (2014), Determinants of Inside and Outside Lobbying Strategies among Swiss and German Interest Groups, Paper drawn on research conducted within the framework on a national competence center in research (NCCR).

\section{Hasil Wawancara}

Wawancara dengan M. Itqonul Hakim, Sekretaris AKDP Kabupaten Pati.

Wawancara dengan Karyo, mantan Kades Tlogoayu dan Pengurus AKDP Kabupaten Pati. 